\title{
A AULA DE GEOGRAFIA NO ENSINO MÉDIO E SUAS RESSIGNIFICAÇÕES
}

\author{
Lidiane Bezerra Oliveira ${ }^{1}$ \\ Armstrong Miranda Evangelista ${ }^{2}$
}

\section{INTRODUÇÃO}

A aula expositiva de Geografia tem se caracterizado historicamente pelo aspecto tradicional; por ser conduzida unilateralmente pelo professor, há pouca participação dos estudantes, cabendo-Ihes ouvir silenciosamente a preleção do primeiro. A aula de Geografia era considerada meramente transmissiva e mnemônica, cabendo aos estudantes memorizar nomes de termos geográficos, como capitais de países e características naturais de espaços distantes de sua realidade.

Com o passar do tempo, tal modelo de aula ganhou diversificação e um novo sentido em relação ao processo de aprendizagem dos estudantes, atribuindo-lhes maior protagonismo na construção do conhecimento. As novas abordagens didáticas reconhecem a importância da aula expositiva para 0 processo de ensino/aprendizagem de Geografia, mas sem restringi-la apenas à transmissão de informações, valorizando a participação do estudante, visto que estes passam a problematizar os conteúdos abordados nas aulas de Geografia. Como diz Libâneo (1994), a aula favorece a organização do ensino, e cria condições para que sejam assimilados novos conhecimentos, habilidades, atitudes e convicções.

A problemática desta investigação consistiu em entender as características da aula expositiva, desenvolvida pelos professores de Geografia do Ensino Médio de Teresina-PI, e se apresentam variações conforme as propostas renovadas do método de exposição. Este estudo ${ }^{3}$ tomou como pressuposto uma questão maior que envolve os processos internos de qualidade do trabalho docente. Preocupa-nos a situação atual vivenciada pelo país no Ensino Médio, a necessidade de aperfeiçoar

\footnotetext{
${ }^{1}$ Professora do Instituto Federal do Piauí. Mestre pelo Programa de Pós-Graduação em Geografia da Universidade Federal do Piauí. E-mail: lidianeoliveira@ifpi.edu.br

${ }^{2}$ Docente do Programa de Pós-Graduação em Geografia, da Universidade Federal do Piauí. E-mail: armstrong@ufpi.edu.br.

${ }^{3}$ Este artigo possui sua versão original publicada na obra FRANÇA-CARVALHO, A. D. Conversas pedagógicas: reflexões sobre o cotidiano da docência. Teresina, EDUFPI, 2010.
} 
o ensino nesse nível, no sentido de contribuir para a melhor capacitação dos jovens, de formação para a cidadania e de preparação para o trabalho. Acredita-se que um estudo dessa natureza vincula-se às questões externas à escola, filiando-se aos projetos de cunho político/educacional do país. Logo, reconhece-se a necessidade de que se realizem ações endógenas mais efetivas no sistema educacional, sobretudo repensando a prática pedagógica cotidiana realizada nas escolas.

\section{A AULA DE GEOGRAFIA E O MÉtOdo dE EXPOSIÇÃo: tRAÇOS DEFINIDORES}

Pretende-se nessa seção do trabalho apresentar um quadro teórico básico a respeito do modelo tradicional da aula expositiva, aproveitando o conhecimento atual disponível na área educacional e nos textos sobre ensino de Geografia. O intuito é situar o problema da pesquisa na produção teórica sobre o tema em foco, e promover esclarecimentos fundamentais para melhor compreensão dos resultados obtidos no trabalho empírico. Traça-se assim um panorama do caráter do método de exposição, para revelar as restrições e as vantagens que apresenta.

\subsection{A aula expositiva tradicional: contributos da literatura em educação}

O ensino tradicional, de acordo com Libâneo (1994), ficou caracterizado pela transmissão da matéria aos alunos, de modo que eles memorizem o conteúdo ensinado pelo professor. Esta modalidade de ensino está centrada no professor que passa a matéria, e o aluno apenas recebe e reproduz de forma mecânica o que absorveu. Além disso, os conteúdos são direcionados pelo livro didático sem nenhuma referência à vida prática dos estudantes, ou seja, não se tem preocupações em saber se eles estão compreendendo de fato o que está sendo ensinado.

Nesse contexto, a forma mais utilizada pelos professores para transmitir os conteúdos ainda é a aula expositiva, na qual o professor detém "o saber, com o papel de fazer sua 'exposição' aos alunos" (CINTRA, 2012, p. 11). Neste tipo de aula, ainda habitual nos dias atuais, o objetivo principal era expor o máximo de conteúdo possível aos estudantes, e estes deveriam copiar toda a matéria em seus cadernos de modo que contribuísse com a memorização do conteúdo exposto. $O$ professor mantinha sua autoridade, pois era considerado detentor do conhecimento 
e os estudantes apenas ouviam o que este tinha a dizer, em uma relação marcada pela hierarquização.

Nesta modalidade de aula prioriza-se o ensino de dados e fatos que "devem ser aprendidos, literalmente, de modo reprodutivo; não é necessário compreendê-los [...]" (POZO, 2000, p. 24). Desta forma, os dados são aprendidos de forma memorística, por meio do qual o aprendiz passivamente recebe informações que não necessitam de compreensão, sendo armazenadas em sua memória. Segundo o mesmo autor, as características da aprendizagem consistem nos seguintes fatos: cópia literal; alcance por repetição; é adquirida de uma só vez; e é esquecida rapidamente.

Zabala afirma que, "por conteúdos factuais, se entende o conhecimento de fatos, acontecimentos, situações, dados e fenômenos concretos e singulares: a idade de uma pessoa, a conquista de um território, a localização ou altura de uma montanha [...]" (1998, p. 41). Dessa forma, só sabe se o aluno aprendeu se ele for capaz de lembrar exatamente a informação expressa pelo professor. Os conteúdos da aula expositiva, no entanto, pouco poderão contribuir para a aprendizagem destes estudantes, pois tais dados e informações memorizadas poderão rapidamente ser esquecidos. Vale lembrar que estes dados eram expostos de forma desconexa em relação a outros conteúdos, assim como em relação a realidade socioespacial; ou seja, os estudantes não eram estimulados a relacioná-los com os acontecimentos da sua vivência.

A aula expositiva tradicional tomou essas características pelo contexto histórico de sua formação. "Em suma, pode-se afirmar que ela seja um fenômeno histórico-educacional, resultante de uma construção no âmbito da cultura ocidental, [...] que tem cunho interferente e interventor na constituição de uma direção às novas gerações" (ARAÚJO, 2013, p. 67). Com o passar do tempo, esta aula ganhou novos artifícios e ressignificação em relação ao processo de aprendizagem dos estudantes, em que este passa a ser sujeito ativo na construção do conhecimento.

\subsection{A aula expositiva sob o ponto de vista da Geografia Escolar}

As aulas de Geografia se desenvolveram de forma similar ao que já foi discutido anteriormente. Para Kaercher "[...] a maioria de nós, se lembra das aulas de Geografia como algo extremamente enfadonho e desinteressante, porque a única qualidade que se exigia do aluno era uma boa capacidade de memorizar nomes de 
acidentes geográficos [...]" (2003, p. 69). A característica descritiva imperava na aula de Geografia, tornando-a assim decorativa na visão dos estudantes. Essa característica criou raízes tão fortes que, mesmo com algumas mudanças na prática dos professores, ao logo do tempo, a Geografia ainda é considerada como decorativa, o que não atrai a atenção dos estudantes, que, assim, priorizam outras disciplinas.

A aula tradicional de Geografia trata principalmente de conteúdos que estão distantes da realidade e "até da imaginação do alunado" (KAERCHER, 2003, p. 69). Esses conteúdos são repassados aos estudantes sem uma interligação entre o homem e o espaço em que ele vive. Ou seja, os fenômenos naturais (clima, vegetação, relevo, hidrografia) são estudados sem interferência humana, de modo a decorar tipologias e nomenclaturas. Já o homem é estudado a partir dos números e taxas que, de fato, não representam a realidade.

Dessa forma, as aulas de Geografia tornavam-se monótonas, pois o professor se encarregava da tarefa de apenas transmitir conhecimento ao estudante. Assim, enquanto aquele falava das características de diversos países do Mundo, estes apenas ouviam sem ter muita noção nem entendimento do conteúdo abordado. Ainda nos dias atuais isso ocorre, os estudantes anotam tudo o que o professor escreve no quadro, porque depois terão que responder às provas da mesma forma como foi exposto. Diante desta rotina, as aulas de Geografia não atraem o interesse dos estudantes; e, por seu caráter descritivo, é por eles denominada de decorativa.

Apesar das novas tendências pedagógicas, características da aula expositiva tradicional continuam presentes na prática do professor de Geografia na atualidade. Para Cavalcanti (2013), o papel do "professor explicador", o livro didático como única fonte, o mapa como ilustração e instrumento de memorização, a memória como sinônimo de aprendizagem, as definições como referência dos conteúdos etc, são algumas características que ainda se mantêm nas aulas. Libâneo (1994) afirma que grande parte dos professores entende o trabalho docente como ato de transmitir o conteúdo oriundo do livro didático, prendendo-se à sequência: exposição verbal, exercícios e prova.

Callai (2013) afirma que as aulas dos professores de Geografia continuam informativas, com a preocupação de passar informações que, muitas vezes, os estudantes já sabem. Acredita também que os espaços analisados são considerados imutáveis, como se os fenômenos não sofressem transformações ao 
longo do tempo; muitas das análises ainda são moralistas, considerando apenas o próprio discurso sem dar importância aos referenciais teóricos; os dados quantitativos ainda permanecem importantes nas análises populacionais; os mapas são considerados como desenhos neutros, ao invés de auxiliar nas análises dos conteúdos.

Os conteúdos conceituais integram a aula expositiva desde seu modo tradicional, porém, eles são de suma importância para o conhecimento dos estudantes, tanto que continuam presentes, mesmo nas perspectivas inovadoras. $\mathrm{Na}$ forma tradicional, os conteúdos conceituais são vistos como fatos ou dados desligados do contexto, ou seja, apenas definições. Diferente da aprendizagem significativa, que insiste na necessidade de compreensão dos fenômenos, na associação dos conceitos à realidade.

Pozo (2000) afirma que o entendimento dos conteúdos conceituais necessita dos conhecimentos prévios dos estudantes, bem como de atividades que oportunizem o descobrimento e a associação desses conceitos à realidade. $O$ autor considera que apenas a exposição oral do professor não é suficiente para que o aluno compreenda os conceitos; dessa forma, ocorre apenas a memorização temporária. Já na aprendizagem significativa, há uma associação entre conteúdos procedimentais e conteúdos conceituais, nos quais os primeiros encaminham à compreensão do segundo.

O objeto de estudo da Geografia na escola é o espaço em movimento, ou seja, o espaço geográfico, e para que o aluno o compreenda de forma significativa e identifique os fenômenos geográficos em sua realidade é preciso que, durante a aula, sejam criadas situações de aprendizagens que ajudem a fazer esta leitura de mundo. A aula expositiva tradicional pouco contribui para isto, visto que a memorização não propõe a compreensão ou interpretação dos fenômenos. Dessa maneira, a aula expositiva proposta pelas concepções pedagógicas inovadoras é um caminho promissor para que o estudante compreenda e interprete o espaço geográfico, pois as situações de aprendizagem serão desenvolvidas com o auxílio do professor; e, neste processo, eles ensinarão os conceitos de modo a identificá-los em seu cotidiano.

Diferentemente do que se exigia na aula expositiva tradicional, os conceitos discutidos na aula de Geografia devem ser compreendidos para que sejam reconhecidos e utilizados no cotidiano dos estudantes; isto é, que eles sejam 
capazes de fazer a leitura do espaço geográfico no seu dia a dia, utilizando os conceitos aprendidos durante a aula de Geografia. Para Cavalcanti: "Os conceitos geográficos são instrumentos básicos para a leitura de mundo do ponto de vista geográfico" (2002, p. 15). Por sua vez, Callai (2013) pondera que com os conteúdos conceituais, os estudantes podem ir além da definição, usando-os como instrumento de interpretação e compreensão da realidade em que vive. Kaercher (2003) afirma que para compreender o espaço é preciso problematizar os elementos que o compõem; trazer a realidade cotidiana para a sala de aula e não fazer da aula uma simples reprodução.

As concepções pedagógicas inovadoras contribuíram sobremaneira para melhorar a aula de Geografia, de modo que as mudanças ocorridas no formato da aula ajudaram à melhor compreensão dos temas geográficos. Afirma-se, neste momento, que a aula expositiva pode revestir-se de fecundidade e complexidade quando investe no aspecto relacional entre os atores que convivem na sala de aula, posto que promove trocas cognitivas e socioemocionais no partilhar das experiências vivenciadas por professores e estudantes.

\section{A AULA EXPOSITIVA DE GEOGRAFIA EM SUA VERSÃO INTERATIVA E DIALÓGICA}

Destaque-se inicialmente que a literatura oferece reflexões valiosas de cunho filosófico e análises científicas consistentes sobre a importância da conversação durante aula, a exemplo dos estudos realizados no campo da Psicologia construtivista. Tais estudos precisam ser reconhecidos pelos professores, confrontados com as experiências docentes no cotidiano da aula para que possam despender esforços de compreensão de ações tradicionais arraigadas que se tornam sérios empecilhos à modificação e melhoria do exercício profissional.

\subsection{A aula expositiva dialógica: subsídios teóricos}

A aula pode ser considerada um momento de organização do processo educativo, que, para Silva, é "[...] tempo e espaço de aprendizagem, de desconstrução e construção [...]" (2013, p. 36). Libâneo complementa que "na aula se criam, se desenvolvem e se transformam, as condições necessárias para que os estudantes assimilem conhecimentos, habilidades, atitudes e convicções e, assim, desenvolvem suas capacidades cognoscitivas" (1994, p. 177). De acordo com 
Fernandes (2013), a aula é concebida como uma teia de relações repleta de concepções históricas, conflitos, encontros e desencontros interpostos por relações dialógicas entre professores e estudantes.

As concepções pedagógicas renovadas sugerem que a seja aula estruturada com base no diálogo entre professores e estudantes possibilitando o protagonismo, liberdade e autonomia dos sujeitos. Para Freire (1987), na relação professor/aluno, o diálogo não pressupõe um conjunto de informes a serem depositados no educando, mas uma devolução organizada, sistematizada e acrescentada dos conhecimentos que este lhe trouxe de forma desestruturada.

$\mathrm{Na}$ aula dialógica os conteúdos a serem trabalhados devem levar em consideração as dúvidas e a própria realidade do aprendiz como forma de problematização, pois, dessa forma, este é desafiado a buscar respostas, tanto em nível intelectual, como em relação a suas próprias ações. "É na realidade mediatizadora, na consciência que dela tenhamos, educadores e povo, que iremos buscar o conteúdo programático da educação" (FREIRE, 1987, p. 87). Desse modo, a aula pode ser considerada conscientizadora porque - ao tempo em que os estudantes apreendem os temas trabalhados - tomam consciência em torno dos mesmos em relação a sua própria realidade.

O diálogo surge como elemento norteador para uma educação que visa à humanização das pessoas; ou seja, o educando realiza-se plenamente como sujeito crítico aos fatores presentes em sua realidade, tais como: os sociais, os culturais, econômicos, entre outros. Ensinar partindo das dúvidas e realidade dos estudantes contribui para que este seja preparado para enfrentar o mundo com um olhar crítico.

Nesta aula, o papel do professor consiste em proporcionar desafios aos estudantes, desenvolver junto com eles a capacidade crítica, a curiosidade para perguntar, atuar, reconhecer. Partindo sempre do conhecimento que o aluno já possui, reconstruindo-o para tornar-se um conhecimento crítico. A relação dialógica pressupõe uma troca de saberes entre professores e estudantes, excluindo aquela tradicional ideia de que o professor é o detentor absoluto da verdade, e mais além, neste processo o professor, assim como os estudantes podem aprender no momento da aula.

A aula dialógica, no âmago do processo comunicativo, permite que os sujeitos se pronunciem, questionem ou se contraponham às ideias do outro, para debater por meio de argumentos. Dessa forma, os estudantes possuem total liberdade de 
expor suas ideias, dúvidas e argumentação, frente ao que o professor discute durante a aula.

Coll (2004) afirma que a relação dialógica que se estabelece entre professor e aluno, no processo de comunicação da aula, passa por duas fases diferenciadas até cumprir a construção de significados compartilhados sobre um conteúdo apresentado. A primeira fase está relacionada à conversa inicial do professor com os estudantes sobre o tema, na qual o autor afirma que é comum haver divergências entre as representações do professor e dos estudantes.

Neste contexto, o diálogo entre professor e aluno se torna extremamente relevante, visto que há uma troca intensa de informações, nas quais devem ser conduzidas cognitivamente, para que se transformem em conhecimento. $O$ que o autor descreve nas fases é a produção do conhecimento mediada pelo diálogo entre os sujeitos durante a aula.

Segundo Libâneo (1994), a interação entre o professor e o aluno na aula ocorre considerando-se dois aspectos: os cognoscitivos e os socioemocionais. $O$ primeiro diz respeito à relação entre professor e aluno no processo de ensino e aprendizagem, em que o professor desenvolve a aula levando em consideração o nível de conhecimento dos estudantes a respeito do conteúdo trabalhado. Nesta relação, o professor deve preocupar-se com a forma como se expressa, ou seja, a fala do professor deve estar no nível de entendimento dos estudantes. O professor em sua fala deve incentivar a participação dos estudantes para que, no diálogo, estes possam expressar suas dúvidas e certezas. O autor denomina de "avaliação diagnóstica" a sondagem que o professor faz sobre o que os estudantes conhecem a respeito do conteúdo da aula, ela pode trazer ao professor a noção do nível de conhecimento dos estudantes sobre o conteúdo.

O segundo aspecto leva em consideração os vínculos afetivos que ocorrem entre professor e aluno, assim como as normas que regem esta relação. Para Libâneo a interação entre os sujeitos na aula ocorre em meio a autoridade do professor durante o processo de ensino-aprendizagem, de modo a fecundar a relação educativa e autonomia dos estudantes na participação nesse processo.

A teoria construtivista tem permeado a fundamentação de vários trabalhos sobre ensino. Nesta discussão, feita sobre aula dialógica, tem-se referido bastante à atuação do aluno como sujeito ativo na construção do conhecimento, em uma relação de diálogo com o que o professor aborda durante a aula expositiva. Ao tratar 
sobre a construção do conhecimento no contexto escolar, Coll (2004) estabelece uma relação entre os estudantes, os conteúdos e o professor, denominando-a de triângulo interativo. Nesta relação, os conteúdos são "saberes preexistentes socialmente construídos e culturalmente organizados" (COLL, 2004, p. 119), construídos com o objetivo de facilitar seu entendimento pelos estudantes. Neste processo, o professor desempenha o papel de intermediar as atividades propostas, possibilitando a obtenção de novos conhecimentos. Os estudantes por sua vez têm como atribuição no processo executar a atividade mental de construção do conhecimento, a partir da ressignificação das representações sobre o conteúdo estudado.

Entende-se, portanto, a relevância da associação entre a construção interativa, do professor com os estudantes, à construção da atividade mental dos significados que os conteúdos escolares veiculam.

\subsection{A dialogia na aula de Geografia}

O ensino de Geografia pelo viés crítico se volta para a problematização das questões espaciais, o que implica mais consciência do estudante sobre a organização do espaço geográfico. Segundo Vesentini (2008) não se trata de ensinar fatos, mas levantar questionamentos para que a partir deles os estudantes possam encontrar caminhos para a compreensão do mundo.

Ainda para esse autor, o conhecimento não é o ponto de partida na Geografia crítica escolar, seu ponto de partida é a relação dialética entre realidade e saber. $\mathrm{O}$ saber está direcionado à explicação desta realidade que se origina a partir da leitura crítica e das observações feitas pelo leitor aos aspectos do real. Assim sendo, o conhecimento deve ser elaborado pelo aluno, onde o professor assume o papel de orientar esta construção, contribuindo também para o desenvolvimento de certas habilidades geográficas básicas.

Dessa maneira, para que ocorra o desenvolvimento da aula de Geografia de forma dialógica, deve-se partir das ideias já apontadas anteriormente por Freire (1987), Coll (2004), Vesentini (2001; 2008), entre outros. A contribuição de aspectos do socioconstrutivismo e do construtivismo social, aliada às bases da Geografia crítica, poderá modificar aquele formato de aula tradicional, para uma aula interativa, em que o conhecimento é construído por meio da interação entre professor, 
estudantes e as representações que ambos trazem para serem ressignificadas, partindo de reflexões sobre a realidade vivida desenvolvidas durante a aula.

A aula dialógica pode partir das formas convencionais de aula. "Observa-se, na verdade, um interesse, em considerando a permanência dessas formas, potencializar as oportunidades de um trabalho que possibilite um envolvimento real dos estudantes com as atividades de ensino" (CAVALCANTI, 2002, p. 20). Na concepção construtivista, recomenda-se que a aula seja organizada de forma a motivar a atividade intelectual do estudante e que o leve a problematizar os conteúdos estudados com os aspectos vivenciados por ele em seu meio.

Assim, a aula de Geografia toma um enfoque voltado para a formação de um modo particular de ver a realidade, com base na aprendizagem dos conceitos geográficos como instrumento das formas de ver o mundo. Acrescente-se, entretanto, que a aprendizagem dos conceitos geográficos deve partir do que 0 aluno já conhece com base em sua vivência, como uma forma evolutiva das representações do cotidiano para a formação do conhecimento científico. Isso se deve a importante participação do aluno durante a aula, assim o professor pode captar os significados que os estudantes dão aos conhecimentos geográficos produzidos.

No processo de formação dos conceitos geográficos na aula, é de suma importância a interação do professor com o estudante através da comunicação, pois este, em seu papel de mediador dos conceitos, deve propiciar a expressão de diversos símbolos, valores, saberes e significados, mantendo uma linguagem na qual o aluno compreenda, como também instigue este aluno a problematizar e refletir sobre os conhecimentos adquiridos no seu cotidiano, de forma a dar um significado de caráter científico a esses conhecimentos. Por conseguinte, o diálogo entre professor e aluno é fundamental para a produção de conhecimentos geográficos, tornando ambos como sujeitos ativos na aula.

A forma com a aula dialógica vai sendo estruturada depende da criatividade e flexibilidade do professor em criar estratégias que engajem o aluno no processo de produção do conhecimento, de forma que a relação que os estudantes possuem com os conteúdos, mediados e orientados pelo professor, possam trazer como resultado a construção de conhecimentos que sejam úteis para a sua vida cotidiana e sua formação como cidadão crítico do espaço. Considera-se, portanto, que a aula de Geografia no formato dialógico tem maiores possibilidades de envolver os 
estudantes com os conceitos, contribuindo para que eles participem do processo de construção do seu próprio conhecimento.

\section{CONSIDERAÇÕES FINAIS}

Segundo a literatura o método de exposição é o mais utilizado pelos professores em sala de aula, mas tem se caracterizado historicamente por um perfil tradicional, havendo a transmissão unilateral pelo professor e com pouca participação dos alunos. Embora com o passar do tempo tal modelo de aula tenha experimentado novas variações, constata-se a continuidade de práticas retrógradas fortemente ancoradas na repetição da experiência da cultura escolar.

Os professores de geografia tem se desdobrado na busca de novas formas de efetivar seu trabalho da melhor maneira possível ao enfrentarem as demandas crescentes de atribuições no espaço escolar, nem sempre obtendo os resultados desejados. Uma alternativa promissora para melhoria do trabalho docente consistiria em ressignificar a aula expositiva aproveitando ao máximo o seu potencial metodológico, determinando suas limitações e conhecendo melhor as possibilidades de renovação com base nas contribuições suscitadas pelos estudos sobre esse gênero didático. Acredita-se que o método expositivo tem reconhecido valor para a aprendizagem de geografia, mas para potencializá-lo é necessário que assimile em seu desenvolvimento características interativas, participativas e dialógicas, problematizando-se os conteúdos nas aulas para que os alunos assimilem essas novas ideias de forma significativa.

A aula de Geografia ficou bastante caracterizada pelo estilo tradicional de sua execução, havendo uma ênfase notória no verbalismo, na descrição e na memorização, tornando-a desinteressante e enfadonha. Faz parte mesmo da tradição ser vista pelos alunos e a comunidade como fatigante e decoreba, distanciada da realidade e da experiência vivenciada pelas pessoas. Esse estigma requer dos professores um esforço adicional no processo de ensino dado os pressupostos negativos em relação à aprendizagem da disciplina.

Diante desse cenário, considera-se premente que sejam incorporados na prática docente em geografia o conhecimento disponível nas ciências da educação a respeito da diversificação do método de exposição, bem como os aportes atuais acerca do aperfeiçoamento da relação professor-aluno e, consequentemente, do 
processo de ensino-aprendizagem. É importante ultrapassar a visão tradicional que põe o aluno numa condição de recepção passiva do saber, possibilitando-Ihe protagonizar a produção do conhecimento na escola.

As concepções pedagógicas inovadoras indicam a participação do aluno no processo de aprendizagem. Acredita-se que através do diálogo no momento de exposição haja um melhor entendimento sobre o tema abordado, levando-se em consideração as dúvidas e a própria realidade do aluno como forma de problematização, que é desafiado a buscar respostas a partir da reflexão e associação dos temas geográficos com o seu cotidiano. Assim, na aula de Geografia deve-se propor que os alunos avancem além dos conteúdos conceituais, que também desenvolvam habilidades para interpretar o espaço geográfico. E isto só se torna possível, quando eles participam de forma ativa das atividades desenvolvidas na aula, substituindo as tarefas de memorização pelo aprendizado compreensivo e amplo dos conhecimentos, envolvendo aí os diversos tipos de conteúdo.

\section{REFERÊNCIAS}

ARAÚJO, José Carlos de Souza. Disposição da aula: os sujeitos entre a tecnia e a polis. In. VEIGA, Ilma Passos Alencastro (Org.). Aula: gênese, dimensões, princípios e práticas. 2. ed. Campinas: Papirus, 2013.

BARDIN, Laurence. Análise de conteúdo. Paris: Robert Laffont, 1977.

CALLAI, Helena Copetti. A formação do profissional de Geografia: o professor. ljuí: Unijuí, 2013.

CAVALCANTI, Lana de Souza. Geografia e práticas de ensino. Goiânia: Alternativa, 2002.

. Os conteúdos geográficos no cotidiano da escola e a meta de formação de conceitos. In: ALBUQUERQUE, M. A. M; FERREIRA, J. A. de S. (org.). Formação, pesquisa e práticas docentes: reforma curriculares em questão. João Pessoa: Mídia, 2013.

CINTRA, Carlos A. Reinventando a aula expositiva. São Carlos: Compacta, 2012.

COLL, César; Solé, Isabel. Linguagem, atividade e discurso na sala de aula. In:

COLL, Cesar; MARCHESI, Álvaro; PALACIOS, Jesús. Desenvolvimento

psicológico e educação: psicologia da educação escolar. v. 2. 2. ed. Porto Alegre: Artmed, 2004. 
. Construtivismo e educação: a concepção construtivista do ensino e da aprendizagem. In: COLL, Cesar; MARCHESI, Álvaro; PALACIOS, Jesús.

Desenvolvimento psicológico e educação: psicologia da educação escolar. v. 2. 2. ed. Porto Alegre: Artmed, 2004.

FERNANDES, Cleoni Maria Barboza. À procura da senha da vida-de-senha a aula dialógica? In: VEIGA, Ilma Passos Alencastro (Org.). Aula: gênese, dimensões, princípios e práticas. 2. ed. Campinas: Papirus, 2013.

FREIRE, Paulo. Pedagogia do oprimido. 17. ed. Rio de Janeiro: Paz e Terra, 1987.

FRANÇA-CARVALHO, A. D. Conversas pedagógicas: reflexões sobre o cotidiano da docência. Teresina, EDUFPI, 2010.

GUIMARÃES, Maria Flora. O conto popular. In: BRANDÃO, Helena Nagamine.

Gêneros do discurso na Escola. 4. ed. São Paulo: Cortez, 1999.

KAERCHER, Nestor André. Desafios e utopias no ensino de Geografia. 3. ed. Santa Cruz do Sul: EDUNISC, 1999, 2003 (reimpressão).

A Geografia é o nosso dia a dia. In: Geografia em sala de aula: práticas e reflexões. 4. ed. Porto Alegre: UFRGS, 2003.

LIBÂNEO, José Carlos. Didática. São Paulo: Cortez, 1994.

POZO, Juan Ignácio. A aprendizagem e o ensino de fatos e conceitos. In: COLL, César. Os conteúdos na reforma: ensino e aprendizagem de conceitos, procedimentos e atitudes. Porto Alegre: Artes Médicas, 2000.

VESENTINI, José William. Geografia Crítica e ensino. In: OLIVEIRA, Ariovaldo Umbelino de (Org.). Para onde vai o ensino de Geografia? 7. ed. São Paulo: Contexto, 2001.

Por uma geografia crítica na escola. São Paulo: Autor, 2008.

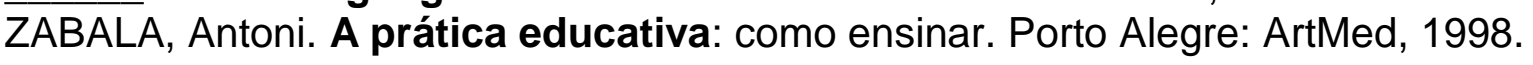

